\title{
The Beck operation in the treatment of angina pectoris
}

\author{
G. SANDLER ${ }^{1}$, B . V. SLESSER, AND C. W. LAWSON \\ WITH THE TECHNICAL ASSISTANCE OF M. CAMERON
}

From the Cardiothoracic Unit, Groby Road Hospital, Leicester

The medical treatment of angina pectoris with coronary vasodilator drugs is generally disappointing, and there is frequently little objective evidence supporting their use (Master, Jaffe, and Dack, 1939 ; Cole, Kaye, and Griffith, 1958 ; Sandler, 1963). Any alternative method of improving blood supply in this condition is therefore of considerable interest, and such an approach has been used by Beck and Leighninger (1955), who established experimentally in dogs that considerable increase in blood flow through the coronary arteries results from partial ligation of the coronary sinus, together with promotion of an artificial pericarditis by chemical irritants. The clinical benefits of this operation were subsequently demonstrated in anginal patients both in reduction of mortality and improvement in morbidity (Beck, Leighninger, Brofman, and Bond, 1958). However, the improvement in angina described in the majority of these patients was based primarily on the subjective information provided by the patients themselves, and little objective evidence was presented to support improvement in myocardial ischaemia. Improvement in anginal pain can result from interference with anatomical pathways of pain sensation (Lindgren and Olivecrona, 1947) or with the central reception of the pain (Sandler, 1961a), but unless there is a corresponding increase in myocardial blood supply the extra exertion possible becomes hazardous. In view of these considerations it was decided to carry out a clinical study of the value of the Beck operation in anginal patients based primarily on an objective assessment of progress by means of exercise tolerance tests with electrocardiographic control.

\section{PATIENTS AND METHODS}

Twenty-five men aged 39 to 60 years underwent operation. All had a typical clinical history of angina

1Present address: St. Helen Hospital, Pogmoor Road, Barnsley, Yorks. pectoris of at least six months' duration, and all but- one showed typical ischaemic depression of the ST $\dot{\omega}$ segment in the electrocardiogram after exercise (Lloyd-Thomas, 1961; Master and Rosenfeld, 1961). Although all the patients were men this was not due $\vec{c}$ to selection but to the successive presentation of suitable patients, and the only selection factor used in the series was to exclude anybody who had marked cardiac enlargement on radiography. Ten patients had electrocardiographic evidence of previous myocardial infarction, and no patient was operated on until at. least one year after the acute episode.

An initial control period of one month of normal activity was allowed to determine the normal trinitrin consumption of the patient, the tablet count at the beginning and end of the month being made always $ᄋ$ by the medical observer. Exercise tolerance tests were $\varrho$ carried out at the end of the control period just before $\vec{\overrightarrow{ }}$ admission for operation, and at regular intervals up 3 to two years after operation. The test used was a $=$ modification of the Master two-step technique and has been discussed in an earlier publication (Sandler, 1961b). Briefly, the patient walks over two steps each 1 foot high, and is allowed to exercise at his own normal walking speed until he is stopped either by $x$ the onset of angina occurring in the majority of patients, or in a few cases by dyspnoea, and the total number of circuits is recorded. An electrocardiogram, $ᄋ$ using chest lead V5, is obtained before starting exercise, immediately afterwards, and then at 30 -second $\mathrm{O}$ intervals until all electrocardiographic signs of ischaemia have disappeared, S-T depression below the iso-electric line of at least $0.08 \mathrm{sec}$. duration is regarded as indicative of myocardial ischaemia, and $\mathrm{N}$ the degree of depression together with its duration is $N$ recorded in each patient. When angina occurs after 0 exercise the time required for the pain to disappear $\mathrm{\omega}$ is also noted.

Patients were seen at three-month intervals aftero operation to enable an exercise tolerance test to be $\frac{\widetilde{D}}{\Phi}$ carried out and to assess the number of trinitrin $\stackrel{\oplus}{\rightarrow}$ tablets used in the intervening period. These tablets were always issued and counted by the observer to 0 obtain as accurate an indication of frequency of $\underset{\mathbb{D}}{\mathbb{D}}$ anginal attacks as possible.

OPERATIVE PROCEDURE In the Beck operation the $\overline{-}$ chest is opened by a left lateral thoracotomy incision. 
The pleura is opened along the upper border of the sixth rib, the posterior end of which is divided, together with the sixth intercostal bundle. The phrenic bundle and pericardial fat are dissected off the pericardium, taking care not to injure the nerve, and a sling is placed around the bundle. The pericardium is widely opened by an L-shaped incision and the heart is inspected with particular reference to the state of the coronary vessels and the presence of old infarcts in the left ventricle. The Beck operation then consists of carrying out the following steps:

1. The internal mammary artery is ligated in the third or fourth space distal to a pericardial branch.

2. The coronary sinus is narrowed down to about $3 \mathrm{~mm}$. using a Beck probe by passing a ligature round the sinus as near its entrance into the right auricle as possible and tying the ligature over the probe. In order to reach the coronary sinus at this level it is necessary to rotate the apex of the heart, and this results in a sudden fall in blood pressure. It is our practice to ask the anaesthetist to give an injection of methedrine immediately before the apex of the left ventricle is rotated, to place the ligature round the coronary sinus, replace the heart for several beats, allowing the blood pressure to recover, and then to tie the ligature, which again necessitates rotating the heart. This manœuvre seems to prevent the troublesome fall in blood pressure which used to occur and which, once developed, might persist throughout the operation. Once the coronary sinus has been narrowed, hair-like capillary vessels, not previously visible, can often be seen over the pericardium.

3. The epicardium of the left ventricle, anterior and posterior surfaces, and as much of the right ventricle as can be reached, are abraded with a small toothbrush with the aim of destroying the epicardium, care being taken not to injure the branches of the coronary vessels. The deep surface of the pericardium is similarly treated.

4. The surface of the left ventricle and the deep surface of the pericardium are now painted with $5 \%$ trichloracetic acid, again taking great care not to put any acid on the coronary vessels.

5. In earlier operations the deep surface of the pericardial fat used to be abraded, painted with trichloracetic acid and, together with the phrenic bundle, placed on the left ventricle and the pericardium sutured over it. This is not now carried out because it may result in partial paralysis of the left diaphragm. The pericardium is closed with one or two stitches only and the phrenic bundle is left in its normal position but the pericardial fat, if present, is buried deep to the pericardium.

The chest is closed with drainage, as a good deal of pleural and pericardial effusion develops from this procedure.

\section{RESULTS}

Table I shows the age of the patients, followup period after operation, and mortality. Seven
T A B L E I

AGE DISTRIBUTION, PERIOD OF FOLLOW-UP AFTER OPERATION, AND MORTALITY

\begin{tabular}{|c|c|c|c|}
\hline Patient & $\begin{array}{c}\text { Age } \\
\text { (years) }\end{array}$ & $\begin{array}{c}\text { Follow-up } \\
\text { Period } \\
\text { (months) }\end{array}$ & Mortality \\
\hline 1 & 55 & 5 & Died. Myocardial \\
\hline 2 & 60 & 18 & Died. Myocardial \\
\hline $\begin{array}{l}3 \\
4\end{array}$ & $\begin{array}{l}53 \\
59\end{array}$ & $\begin{array}{r}24 \\
4\end{array}$ & $\begin{array}{l}\text { Alive } \\
\text { Died. Myocardial } \\
\text { infarction }\end{array}$ \\
\hline $\begin{array}{r}5 \\
6 \\
7 \\
8 \\
9 \\
10 \\
11 \\
12 \\
13 \\
14 \\
15 \\
16 \\
17 \\
18 \\
19 \\
20 \\
21 \\
22 \\
23 \\
24 \\
25\end{array}$ & $\begin{array}{l}56 \\
49 \\
40 \\
55 \\
48 \\
45 \\
43 \\
44 \\
51 \\
49 \\
45 \\
56 \\
39 \\
54 \\
46 \\
51 \\
56 \\
51 \\
47 \\
52 \\
50\end{array}$ & $\begin{array}{r}22 \\
12 \\
12 \\
13 \\
13 \\
13 \\
13 \\
17 \\
20 \\
12 \\
12 \\
14 \\
8 \\
12 \\
13 \\
13 \\
12 \\
14 \\
20 \\
9 \\
28 \\
10\end{array}$ & $\begin{array}{l}\text { Alive } \\
\text { Alive } \\
\text { Alive } \\
\text { Alive } \\
\text { Alive } \\
\text { Alive } \\
\text { Alive } \\
\text { Alive } \\
\text { Alive } \\
\text { Alive } \\
\text { Alive } \\
\text { Died ? Cause } \\
\text { Alive } \\
\text { Alive } \\
\text { Alive } \\
\text { Alive } \\
\text { Alive } \\
\text { Alive } \\
\text { Alive } \\
\text { Alive } \\
\text { Alive }\end{array}$ \\
\hline
\end{tabular}

patients were followed for 18 months or more, and 14 for at least a year. There were no immediate post-operative deaths, but two patients died within six months of operation and one 18 months after operation, all of myocardial infarction. In one patient who died eight months after operation it was not possible to discover the cause.

The mean trinitrin consumption before and after operation is shown in Table II. The mean

T A B LE II

TRINITRIN CONSUMPTION BEFORE AND AFTER OPERATION (MEAN VALUES) IN 25 PATIENTS

\begin{tabular}{|c|c|c|c|c|}
\hline & & \multicolumn{3}{|c|}{ No. of Trinitrin Tablets } \\
\hline \multirow{2}{*}{\multicolumn{2}{|c|}{$\begin{array}{l}\text { Mean } \\
\text { Standard error }\end{array}$}} & Pre-operative & Post-operative & Change \\
\hline & & $\begin{array}{r}18 \cdot 3 \\
2 \cdot 9\end{array}$ & $\begin{array}{l}6.9 \\
1.4\end{array}$ & $\begin{array}{r}-10 \cdot 3 \\
3.8\end{array}$ \\
\hline $\begin{array}{l}\mathbf{t} \\
\mathbf{P}\end{array}$ & $\begin{array}{ll} & . \\
. & \end{array}$ & \multicolumn{2}{|c|}{$>0.15^{1.01}$} & $>0.005^{2.7}<0.01$ \\
\hline
\end{tabular}

values did not differ significantly before and after operation, but when the differences resulting from operation in each individual patient were analysed there was a significant reduction in the number of trinitrin tablets used post-operatively $(P<0.01)$.

The changes in the exercise tolerance tests are shown in Table III and are expressed as mean values for the whole group of patients, and again differences in individual patients were analysed statistically as well as the mean value of the group. 
T A B L E I I I

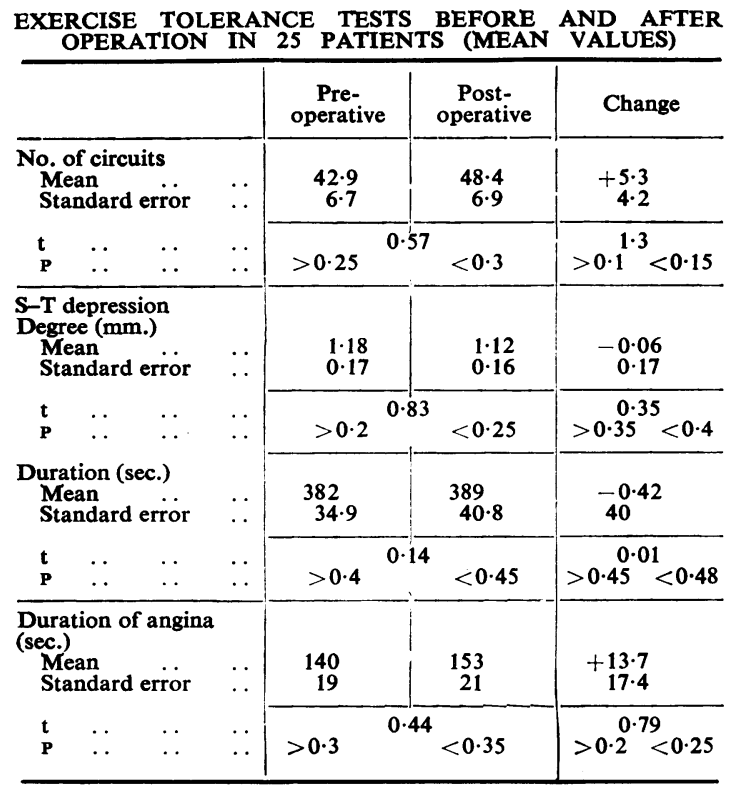

No significant differences were apparent postoperatively in any of the parameters assessedthe number of circuits possible before the development of angina, the degree and duration of angina produced by the exercise.

OPERATIVE FINDINGS Twenty-one out of the 25 patients had rigidity of the left main coronary artery, four with extensive calcification also. Thickening of the right main coronary artery was only slightly less frequent, occurring in 17 patients. Extensive atheroma and calcification of the anterior interventricular artery was present in 24 out of the 25 patients, while the circumflex artery was affected by atheroma in 22 patients. Evidence of myocardial infarction was present in 10 patients and affected the anterior surface only in two patients, posterior surface only in four patients, and both surfaces in four patients. In six of these 10 patients with infarction there was good correlation between electrocardiographic evidence of infarction and the operation findings, while in three other patients with posterior infarction seen at operation a conduction defect pattern only was present in the posterior leads; only one patient had a 'silent' infarction with a normal electrocardiogram. In four cases excessive myocardial irritability was present on manipulation of the heart, but only one of these patients exhibited spontaneous ectopic beats before operation.

\section{DISCUSSION}

The Beck operation has been claimed to have a two-fold function in anginal patients-to prevent sudden death in hearts 'too good to die', and to improve severe anginal pain (Beck and Leighninger, 1961). The concept of the heart 'too good to die' is based on an extensive necropsy study of 500 sudden deaths from coronary occlusion, the majority of which showed no evidence of recent vascular occlusion or myocardial damage (Adelson and Hoffman, 1961). In these cases death has been attributed to fatal ventricular fibrillation triggered off by the electrical instability of the heart resulting from differential oxygenation of various parts of the myocardium, and there is ample experimental evidence to support this 'self-electrocution' mechanism (Beck and Leighninger, 1954). The Beck operation, by stimulating the development of intercoronary anastomoses, evens out the distribution of blood through an ischaemic myocardium and so helps to prevent the development of oxygenation differentials in the myocardium, with the consequent electrical instability, when coronary artery occlusion occurs (Beck and Leighninger, 1955).

In a series of 347 patients the immediate postoperative mortality was 6\% (Beck et al., 1958), and in our much smaller series we had no immediate post-operative deaths. Comparison of the four-year mortality of 206 operated patients with 7,400 anginal patients who had no operation shows a mortality of approximately one-half in the operated patients (Beck and Leighninger, 1961). In our limited series the mortality was $16 \%$ over the period of the study, only slightly higher than Beck and Leighninger's own two-year operation results and less than the two-year mortality of $25 \%$ in the non-operated patients in Beck and Leighninger's series.

The second main aim of the Beck operation, the relief of severe anginal pain, was supported by the improvement in anginal attacks which occurred in the vast majority of the 337 operated patients reported by Beck et al. (1958). However, in view of the lack of direct correlation between frequency and severity of angina and degree of coronary insufficiency (Russek, Zohman, and Dorset, 1955) and the high susceptibility of anginal patients to new drugs or procedure (Cole et al., 1958), relief of anginal pain is a poor criterion of the effect of any procedure in improving myocardial ischaemia. A more objective assessment of improvement must be made which relies as little as possible on the patient's 
own interpretation of his progress and which also gives some indication of the effect on the myocardial ischaemia. The present study has been based on such an assessment by exercise tolerance tests and has indeed shown a significant reduction in the frequency of angina reported by the patients after operation. There has been, however, no evidence of a concurrent improvement either in the amount of exercise possible before angina develops or in the electrocardiographic changes of myocardial ischaemia resulting from exercise. The subjective improvement in the angina may well be due to a combination of the suggestibility of the patients following a new procedure together with some real diminution of anginal pain by operative interference with the anatomical pathways of pain sensation.

\section{SUMMARY}

The value of the Beck operation, which consists in partial ligation of the coronary sinus and production of a chemically induced pericarditis, has been investigated in 25 men suffering from angina pectoris. Assessment was made subjectively by changes in trinitrin consumption and objectively by exercise tolerance tests with electrocardiographic control. The follow-up period ranged from four to 28 months.

There was no immediate post-operative mortality, but four men died at intervals from four to 18 months after operation, three of them with myocardial infarction. Although there was a significant reduction in frequency of anginal attacks post-operatively, there was no concurrent improvement in myocardial ischaemia on the electrocardiogram after exercise.

The results suggest that the Beck operation has a favourable effect on the mortality from angina pectoris probably by producing a more even distribution of coronary blood supply through the myocardium. There is no evidence, however, of improvement in myocardial ischaemia following exercise.

\section{REFERENCES}

Adelson, L., and Hoffman, W. (1961). Sudden death from coronary disease. J. Amer. med. Ass., 176, 129.

Beck, C. S., and Leighninger, D. S. (1954). Operations for coronary artery disease. Ibid., 156, 1226.

- (1955). Scientific basis for the surgical treatment of coronary artery disease. Ibid., 159, 1264. (1961). The coronary patient wants better treatment. Med. Tms (N.Y.), 89, 17.

Brofman, B. L., and Bond, J. F. (1958). Some new concepts of coronary heart disease. Results after surgical operation. J. Amer. med. Ass., 168, 2110.

Cole, S. L., Kaye, H., and Griffith, G. C. (1958). Assay of antianginal agents-the rapport period. Ibid., 168, 275.

Lindgren, I., and Olivecrona, H. (1947). Surgical treatment of angina pectoris. J. Neurosurg., 4, 19.

Lloyd-Thomas, H. G. (1961). The exercise electrocardiogram in patients with cardiac pain. Brit. Heart J., 23, 561.

Master, A. M., Jaffe, H. L., and Dack, S. (1939). The drug treatment of angina pectoris due to coronary artery disease. Amer. J. med. Sci., 197, 774.

— and Rosenfeld, I. (1961). Criteria for the clinical application of the 'two-step' exercise test. J. Amer. med. Ass., 178, 283.

Russek, H. I., Zohman, B. L., and Dorset, V. J. (1955). Objective evaluation of coronary vasodilator drugs. Amer. J. med. Sci. $229,46$.

Sandler, G. (1961a). Clinical evaluation of pheniprazine in angina pectoris. Brit. med. J., 1, 792.

(1961b). Clinical evaluation of propatylnitrate in angina pectoris. Ibid., 2, 1741.

(1963). Organic nitrates and other drugs for angina. Drug and Therapeutics Bulletin, 1, 34. 